\title{
PENDUGAAN KEKAKUAN KAYU BORNEO DENGAN METODE GELOMBANG ULTRASONIK
}

\author{
Prediction Stifness of Borneo Wood with Ultrasonic Wave Method \\ Syahidah dan Tekat Dwi Cahyono
}

\begin{abstract}
Borneo wood is a name for various species commercial wood. The aimed of this study are measured stifness (MOE) of borneo wood using non destructive method i.e. ultrasonic wave. Fiveteen beam sample were produced from borneo wood about $8 \mathrm{~cm}$ thick and $12 \mathrm{~cm}$ width with $400 \mathrm{~cm}, 250 \mathrm{~cm}$ and $150 \mathrm{~cm}$ length. Beam with $250 \mathrm{~cm}$ and $150 \mathrm{~cm}$ length produced from beam with $400 \mathrm{~cm}$ length after stifness test have done using ultrasonic (dynamic test) and UTM (static test). Result showed that dynamic MOE of borneo wood for $400 \mathrm{~cm}, 250 \mathrm{~cm}$ and $150 \mathrm{~cm}$ length, are $19.10 \mathrm{G} . P a, 18.48 \mathrm{G} . P a$ and $15.90 \mathrm{G} . \mathrm{Pa}$, respectively. Wood about $400 \mathrm{~cm}$ and $150 \mathrm{~cm}$ length were different significantly. Result also showed that dynamic MOE of borneo wood 30\% higher than static MOE at vertical position test for beam with $400 \mathrm{~cm}$ length and $20 \%$ higher for horisontal position at the same testing method.
\end{abstract}

Key words : Borneo wood, stifness, ultrasonic, MOE, MOR

\section{PENDAHULUAN}

Penggunaan kayu sebagai bahan konstruksi di Indonesia masih menjadi pilihan utama bagi masyarakat. Hal ini disebabkan karena kayu memiliki banyak kelebihan misalnya mudah dikerjakan dan dirakit dengan alat sederhana, cukup kuat, memiliki nilai estetika dan beratnya juga relatif ringan. Meskipun demikian, kayu perdagangan di Indonesia memiliki aneka ragam jenis dan ukuran dengan variasi yang tinggi pada kualitas dan penampilan akibat sifat fisis, mekanis dan cacat bawaan yang sangat beragam (Surjokusumo, dkk., 2003).

Pemanfaatan kayu sebagai bahan bangunan harus memiliki sifat mekanis sesuai dengan persyaratan struktural yang baik. Persyaratan struktural yang baik adalah kayu tersebut mampu menahan beban dengan aman dalam jangka waktu yang direncanakan. Untuk menduga kualitas kayu digunakan dua cara yaitu pengujian secara destruktif dan pengujian non destruktif. Untuk memenuhi syarat sebagai bahan konstruksi bangunan, maka hasil pengujian harus memenuhi kriteria/standar mutu yang telah ditetapkan demi keamanan dan kenyamanan pemakai bangunan. Kayu bermutu konstruksi struktural dapat diperoleh dengan melakukan pemilahan (grading) yaitu kegiatan memeriksa dan menilai kondisi (cacat) kayu bangunan atau struktural untuk desain konstruksi sehingga tidak salah duga mengenai kekuatannya. Pemilahan pada prinsipnya adalah mereduksi variasi yang muncul dengan mengklasifikasikan kayu ke dalam beberapa kelas mutu, di mana kegiatan pemilahan kayu konstruksi diarahkan kepada pengujian non destruktif.

Saat ini telah ada berbagai standar pemilahan kayu di antaranya Peraturan Konstruksi Kayu Indonesia (PKKI) tahun 1961, Standar Kehutanan Indonesia (SKI C-bo-010) tahun 1987, ASTM (American Society for Testing Materials) D 245 tahun 2000 dan saat ini Indonesia sedang menyempurnakan SNI (Standar Nasional Indonesia) tahun 2002 tentang Tata Cara Perencanaan Konstruksi Kayu Indonesia. Adapun metode yang telah digunakan mencakup metode visual (risalah cacat) dan masinal menggunakan alat bantu mesin (machine stress rating) seperti Mesin Pemilah Kayu Panter MPK 5 dan Sylvatest Duo (yang menggunakan gelombang ultrasonik). Skala karakteristik struktur kayu dan kebutuhan resolusi pada suatu metode berdasarkan panjang gelombang $-\lambda-(m)$ untuk ultrasound/ultrasonic yaitu pada panjang gelombang $(\mathrm{m}) 10^{-2} \ldots 10^{3}$ dengan skala struktur kayu mesoskopis (pohon), makroskopis dan mikroskopis. Pengujian yang dilakukan merupakan pengujian non-destruktif berupa pengujian masinal yang menggunakan 
prinsip gelombang ultrasonik dengan alat Sylvatest Duo.

Penelitian ini bertujuan untuk menduga kekakuan (MOE) kayu borneo pada berbagai panjang yaitu $400 \mathrm{~cm}, 250 \mathrm{~cm}$ dan $150 \mathrm{~cm}$, membandingkan nilai MOE ultrasonik dengan metode pengujian lain (Panter, One Point Loading dan Two Point Loading) dan melihat model hubungan antara $v$ (kecepatan rambat gelombang ultrasonik dengan nilai MOE apparent OPL dan TPL.

\section{BAHAN DAN METODE}

Penelitian ini menggunakan bahan berupa kayu borneo sebanyak 15 balok dengan ukuran tebal $12 \mathrm{~cm}$, lebar $8 \mathrm{~cm}$ dan panjang $400 \mathrm{~cm}$. Pengujian secara non destruktif metode gelombang ultrasonik dilakukan dengan menggunakan alat sylvatest duo, sementara itu pengujian kekakuan statis kayu menggunakan mesin uji UTM merk Baldwin.

Pengujian gelombang ultrasonik dilakukan dengan menempatkan 2 buah transduser pada kedua ujung contoh uji. Transduser terdiri atas transduser pengirim dan transduser penerima. Selanjutnya, dengan dibangkitkan oleh alat, gelombang ultrasonik mengalir dari transduser pengirim yang kemudian diterima oleh transduser penerima. Waktu tempuh gelombang dan panjang/jarak tempuh dicatat untuk kemudian dihitung kecepatan gelombangnya. Pengujian dilakukan tiga kali ulangan untuk masing-masing titik pada kayu yang terdiri atas 3 titik tiap sisinya. Volume dan berat kayu diukur untuk mengetahui kerapatan contoh uji. Kekakuan kayu dinamis dihitung berdasarkan rumus $\mathrm{MOE}=\left(\mathrm{v}^{2} \times \rho\right) / \mathrm{g}$. Sementara itu kekakuan statis (MOEs) dihitung untuk dua kondisi pengujian, yaitu OPL dan TPL. MOEs OPL dan TPL masing-masing dihitung dengan menggunakan rumus MOEs OPL $=\left(\Delta \mathrm{PL}^{3}\right) /\left(4 \Delta y b h^{3}\right)$, MOEs TPL $=\left(\mathrm{P}^{\prime} \mathrm{a} \quad\left(3 \mathrm{~L}^{2}-\right.\right.$ $\left.\left.h a^{2}\right)\right) /\left(4 \Delta y_{b h}^{3}\right)$.

\section{HASIL DAN PEMBAHASAN}

\section{Pengujian Kekakuan Kayu dengan Metode Gelombang Ultrasonik}

Hasil penelitian menggunakan metode ultrasonik yang diperoleh kemudian diolah dan disajikan pada Tabel 1.

Pada Tabel 1 terlihat bahwa panjang balok $400 \mathrm{~cm}$ memiliki nilai MOE terbesar, yaitu 19,10 G.Pa sedangkan yang terkecil pada panjang balok $150 \mathrm{~cm}$ yaitu 15,90 G.Pa. Jika dibandingkan pada saat pengukuran kecepatan dengan sylvatest duo, terlihat rata-rata kecepatan antara panjang balok $250 \mathrm{~cm}$ dan $150 \mathrm{~cm}$ tidak terlalu berbeda, yaitu $4729 \mathrm{~m} / \mathrm{s}$ dan 4745,7 m/s. Namun karena sebaran data kecepatan pada panjang balok $250 \mathrm{~cm}$ lebih beragam ditunjukkan dengan standar deviasi yang lebih besar, maka rata-rata nilai MOE antara panjang balok $250 \mathrm{~cm}$ dan $150 \mathrm{~cm}$ sangat berbeda, yaitu 18,48 G.Pa dan 15,90 G.Pa.

Selanjutnya dilakukan analisis lanjutan untuk menguji beda nilai MOE di antara panjang balok yang diujikan dalam penelitian, karena nilai MOE untuk panjang $400 \mathrm{~cm}$ dan $250 \mathrm{~cm}$ memiliki nilai yang hampir sama. Uji yang dilakukan adalah uji-t berpasangan antara panjang balok $400 \mathrm{~cm}$ dan $250 \mathrm{~cm}$, balok $250 \mathrm{~cm}$ dan $150 \mathrm{~cm}$ dan balok 400 $\mathrm{cm}$ dan $150 \mathrm{~cm}$. Dari hasil uji-t terilhat bahwa pasangan nilai MOE $400 \mathrm{~cm}$ dan $250 \mathrm{~cm}$ tidak berbeda nyata, demikian juga untuk pasangan nilai MOE $250 \mathrm{~cm}$ dan $150 \mathrm{~cm}$. Hal ini berarti nilai MOE kedua pengujian tersebut sama, sedangkan untuk pasangan nilai MOE $400 \mathrm{~cm}$ dan $150 \mathrm{~cm}$, hasil pengujian menunjukkan berbeda sangat nyata. Hal ini berarti nilai MOE antara pengujian bentang 400 $\mathrm{cm}$ dan $250 \mathrm{~cm}$ berbeda.

Halabe et al. (1995) dalam Oliveira et al. (2002) menyatakan bahwa kayu merupakan suatu material yang bersifat viskoelastis dan memiliki kemampuan menyerap pukulan yang tinggi (highly impact-absorbent material), kekuatan elastisitas kayu berbanding lurus terhadap perubahan jarak (displacement) dan kekuatan berbanding lurus terhadap kecepatan (velocity). Oleh karena itu,

Table 1. MOE Average at Various Length of Borneo Wood Beam with Ultrasonic Method Testing

\begin{tabular}{lcccc}
\hline \multirow{2}{*}{ Testing Parameter } & & \multicolumn{3}{c}{ Sample Length } \\
\cline { 3 - 5 } & Rata-rata & $400 \mathrm{~cm}$ & $250 \mathrm{~cm}$ & $150 \mathrm{~cm}$ \\
\hline Kecepatan (m/detik) & SD & 5084 & 4729 & 4746 \\
\multirow{2}{*}{ MOE (GPa) } & Rata-rata & $19,10^{\mathrm{a}}$ & 1355,62 & 451,52 \\
& $\mathrm{SD}$ & 5,23 & $18,48^{\mathrm{ab}}$ & $15,90^{\mathrm{b}}$ \\
& & & 6,71 & 4,1 \\
\hline
\end{tabular}


ketika gaya diberikan dalam waktu singkat material menunjukkan tingkah laku elastisitas yang solid, sedangkan pada aplikasi gaya yang lebih lama tingkah lakunya serupa dengan viskous cair. Tingkah laku ini lebih terlihat pada pengujian lentur statis pada jangka waktu lama dibandingkan dengan uji ultrasonik yang relatif singkat. Ada beberapa variabel yang mempengaruhi kecepatan rambat gelombang ultrasonik (V) pada kayu, antara lain karakteristik mikrostruktural kayu dan komposisi kimia yang disebabkan oleh perbedaan jenis kayu, kondisi tanah dan cuaca (Oliviera et al., 2002). Beberapa faktor yang dapat mempengaruhi kecepatan gelombang ultrasonik adalah (Karlinasari, 2003):

1. kadar air; peningkatan kadar air menyebabkan peningkatan kecepatan gelombang

2. arah serat; kecepatan gelombang lebih cepat pada arah longitudinal (searah serat), kemudian pada arah radial dan yang terlama adalah pada arah tangensial. Selain itu semakin panjang serat semakin cepat gelombang mengalir

3. dinding sel dengan porositas dan permeabilitas yang tinggi akan memperlambat kecepatan gelombang ultrasonik

4. daerah kristalin pada dinding sel (kaya akan selulosa) lebih cepat mengalirkan gelombang ultrasonik dibandingkan dengan daerah amorf (kaya akan lignin dan hemiselulosa).

Parameter yang digunakan dalam pengujian non-destruktif metode gelombang ultrasonik adalah kecepatan rambat gelombang ultrasonik. Kecepatan gelombang ultrasonik dibangkitkan oleh getaran dengan parameter yang diukur berupa waktu perambatan. Kecepatan rambat gelombang menjadi dasar dalam pendugaan kekakuan kayu, dalam hal ini kekakuan kayu berkorelasi erat dengan kekuatan kayu.

\section{Perbandingan Nilai MOE Dinamis dengan MOE Statis.}

Hasil analisis pengujian MOE dengan ultrasonik kemudian dibandingkan dengan beberapa pengujian lainnya. Pengujian lain yang dimaksud adalah pengujian pembebanan terpusat $(\mathrm{OPL})$, dan pembebanan terbagi dua (TPL). Dari data yang diperoleh dengan metode pengujian lainnya, secara umum, MOE dinamis memiliki nilai yang relatif lebih tinggi jika dibandingkan dengan MOE statis karena hanya merupakan pendugaan (estimasi). Hasil pengukuran MOE dinamis dan MOE statis disajikan dalam Tabel 2.

\begin{tabular}{|c|c|c|c|}
\hline \multirow[t]{2}{*}{ No. } & \multirow[t]{2}{*}{ Testing Mehtod } & \multicolumn{2}{|c|}{$\begin{array}{c}\text { Average of MOE } \\
\text { (GPa.) }\end{array}$} \\
\hline & & Horizontal & Vertical \\
\hline 1. & Ultrasonik & 19,10 & \\
\hline 2. & $\begin{array}{l}\text { One Point Loading } \\
\text { (OPL) }\end{array}$ & 14,43 & 12,94 \\
\hline 3. & $\begin{array}{l}\text { Third Point Loading } \\
\text { (TPL) }\end{array}$ & 15,99 & 12,50 \\
\hline
\end{tabular}

Perbedaan pengujian pembebanan terpusat (one point loading, OPL), dan pembebanan terbagi dua (two point loading, TPL) disebabkan oleh pengaruh gaya geser. Rata-rata hasil pengujian TPL adalah 15,99 G.Pa, sedangkan OPL adalah sebesar $14,43 \mathrm{G} . \mathrm{Pa}$. Hal ini sejalan dengan teori bahwa terdapat perbedaan dari metode pengujian OPL dan TPL dimana pada OPL terdapat gaya geser yang berpengaruh pada defleksi dan pada akhirnya akan mempengaruhi nilai MOE yang dihasilkan, sedangkan pada TPL tidak terdapat gaya geser di tengah bentang di antara dua beban sehingga defleksi yang terjadi pada posisi tersebut hanya disebabkan oleh lentur murni (Bahtiar, 2005).

Perbedaan nilai antara pengujian pada posisi tegak dan rebah disebabkan tingkat kekakuan yang berbeda. Pada posisi tegak, dimensi tebal lebih besar dibandingkan dengan posisi rebah, sehingga kekakuan kayu akan lebih besar pada bentang yang sama. Persentase perbedaan pengujian ultrasonik dengan pengujian OPL dan TPL dapat dilihat pada Gambar 2.

Pada gambar tersebut terlihat bahwa MOE ultrasonik lebih mendekati hasil yang diperoleh dari pengujian rebah, baik OPL maupun TPL, yaitu $16,28 \%$ untuk TPL dan $24,61 \%$ untuk OPL. Sedangkan untuk posisi tegak, di mana dimensi tebal lebih besar, maka perbedaan nilai juga semakin besar, yaitu 34,5\% untuk TPL dan $32,25 \%$ untuk OPL.

\section{Korelasi antara Kecepatan Gelombang Ultrasonik dengan Pengujian OPL dan TPL}

Untuk mengetahui apakah suatu model hubungan tepat dan memiliki hubungan linear antara variabelnya dapat dicari dari nilai koefisien korelasi ( $r$ ) di mana semakin besar nilai tersebut maka hubungan antara variabel $\mathrm{x}$ dan $\mathrm{y}$ yang 


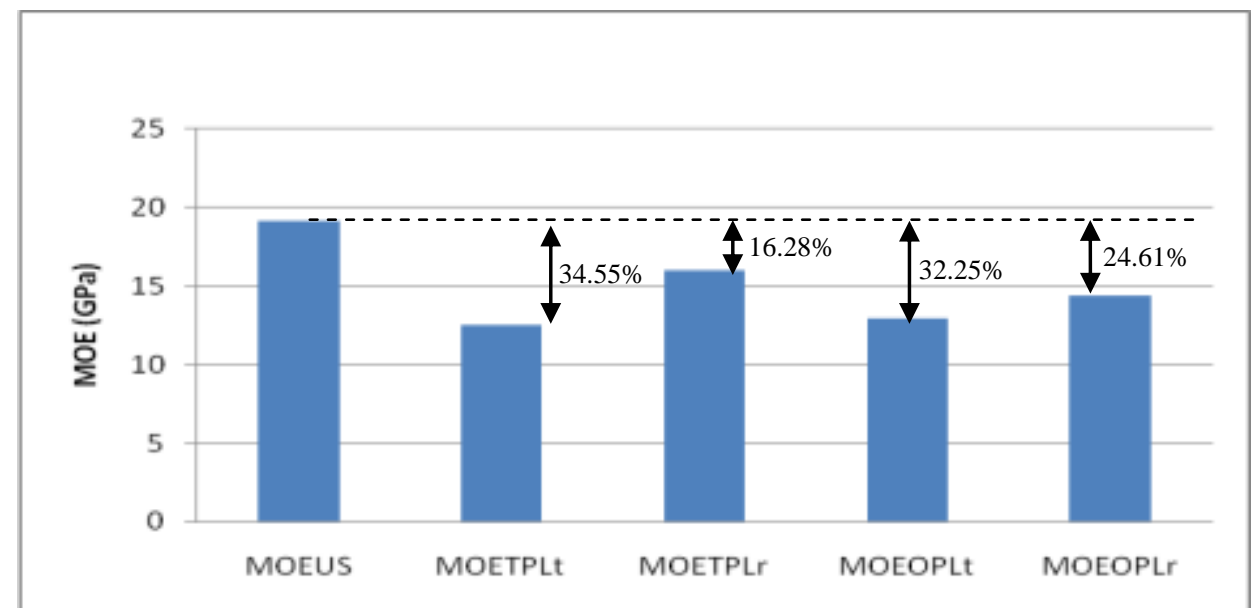

Remarks: $\quad$ MOEUS $=$ MOE Ultrasonik, MOETPLt $=$ MOE of TPL at vertical position, MOETPLr $=$ MOE of TPL at horisontal position, MOEOPLt $=$ MOE of OPL at vertical position, MOEOPL $r=$ MOE of OPL at horisontal position.

Figure 2. Comparative between MOE US and MOEapp at OPL and TPL testing method

dianalisa semakin erat atau linear, sedangkan koefisien determinasi $\left(R^{2}\right)$ digunakan untuk menunjukkan tingkat ketepatan suatu model hubungan regreasi linear (Hines and Douglas, 1989). Perlu diingatkan bahwa koefisien korelasi antara dua peubah adalah suatu ukuran hubungan linear antara kedua peubah tersebut, sehingga nilai $r=0$ berimplikasi tidak adanya hubungan linear, bukan berarti bahwa antara kedua peubah itu tidak terdapat hubungan, sedangkan koefisien determinasi $\left(R^{2}\right)$ menunjukkan seberapa besar keragaman dalam nilai-nilai y dapat dijelaskan oleh hubungan linearnya dengan nilai $\mathrm{x}$ (Walpole, 1995). Model-model hubungan antara pengujian OPL dan TPL baik pada posisi tegak maupun rebah dengan pengujian ultrasonik disajikan pada Tabel 3.

Table 3. Correlation Model Between Ultrasonic Testing Method and OPL and TPL Testing Method at Vertical and Horisontal Position

\begin{tabular}{lcc}
\hline No & Correlation Model & $\mathrm{R}^{2}$ \\
\hline 1. & MOEsTPLr $=29,07 \mathrm{v}+4618$ & 0,053 \\
2 & MOEsOPLr $=3,625 \mathrm{v}+5031$ & 0,001 \\
3 & MOEsTPLt $=3,414 \mathrm{v}+5041$ & 0,000 \\
4 & MOEsOPLt $=35,22 \mathrm{v}+4628$ & 0,087 \\
\hline
\end{tabular}

Remarks:

MOEsTPLr = Static MOE of TPL at horisontal position, MOEsOPLr = Static MOE of OPL at horisontal position, MOEsTPLt $=$ Static MOE of TPL at vertical position, MOEsOPLt $=$ Static MOE of OPL at vertical position, $v=$ ultrasonic wave velocity
Pada Tabel 3 di atas terlihat bahwa model hubungan antara kecepatan rambat gelombang ultrasonik (V) dalam menduga MOE apparent (MOEapp) baik pada pengujian OPL maupun TPL memiliki nilai koefisien determinasi $\left(R^{2}\right)$ yang rendah, semuanya di bawah $10 \%$. Dengan hasil ini dapat dikatakan bahwa $v$ (kecepatan gelombang ultrasonik) secara individu tidak mampu menjelaskan MOE apparent, baik untuk pengujian OPL maupun TPL.

Sementara itu untuk model hubungan antara MOE ultrasonik dengan MOE apparent OPL maupun TPL baik pada posisi tegak maupun rebah disajikan dalam Tabel 4. Pada Tabel 4 terlihat bahwa antara MOE ultrasonik dengan MOE apparent baik pada posisi tegak maupun rebah memiliki koefisien determinasi yang rendah, tetapi masih lebih tinggi dibandingkan dengan model

Table 4. Correlation Model Between Ultrasonic MOE and OPL and TPL MOE at Vertical and Horisontal Position

\begin{tabular}{lcc}
\hline No & Correlation Model & $\mathrm{R}^{2}$ \\
\hline 1. & MOEsTPLr $=0,757 \mathrm{MOEd}+6,99$ & 0,275 \\
2 & MOEsOPLr $=0,655 \mathrm{MOEd}+9,639$ & 0,369 \\
3 & MOEsTPLt $=1,335 \mathrm{MOEd}+2,396$ & 0,516 \\
4 & MOEsOPLt $=1,091 \mathrm{MOEd}+4,978$ & 0,637 \\
\hline
\end{tabular}

Remarks:

MOEsTPLr = Static MOE of TPL at horisontal position, MOEsOPLr = Static MOE of OPL at horisontal position, MOEsTPLt $=$ Static MOE of TPL at vertical position, MOEsOPLt $=$ Static MOE of OPL at vertical position, MOEd $=$ MOE ultrasonic 
hubungan dengan kecepatan gelombang ultrasonik. Koefisien determinasi terbesar terdapat pada hubungan antara MOE ultrasonik dengan MOE apparent OPL pada posisi tegak, yaitu 63,7\% sedangkan yang terendah terdapat pada model hubungan antara MOE ultrasonik dengan MOE apparent TPL pada posisi rebah, yaitu $27,5 \%$. Dari hasil ini dapat dikatakan bahwa hubungan MOE ultrasonik dengan MOE apparent pengujian OPL dan TPL memiliki korelasi yang tidak tinggi.

\section{KESIMPULAN}

Kesimpulan yang dapat diambil dari pendugaan kekakuan kayu menggunakan gelombang ultasonik adalah sebagai berikut :

1. Kayu borneo memiliki rata-rata nilai MOE 19,10 G.Pa untuk bentang $400 \mathrm{~cm}, 18,48$ G.Pa untuk bentang $250 \mathrm{~cm}$ dan 15,90 G.Pa untuk bentang $150 \mathrm{~cm}$.

2. Jika dibandingkan dengan metode pemilahan dan pengujian kayu lainnya, maka pengujian ultrasonik memberikan nilai MOE rata-rata terbesar yaitu 19,10 G.Pa untuk bentang 400 $\mathrm{cm}$, kemudian diikuti oleh pengujian TPL dengan nilai MOE rata-rata sebesar 15,99 G.Pa, selanjutnya pengujian OPL dengan nilai MOE rata-rata sebesar $14,43 \mathrm{G} . \mathrm{Pa}$

3. Kecepatan rambat gelombang ultrasonik (V) secara tunggal kurang baik dalam menjelaskan MOE, baik dalam pengujian OPL maupun TPL. Demikian pula hubungan MOE ultrasonik dan MOE OPL maupun TPL baik dalam posisi tegak maupun posisi rebah memiliki korelasi yang tidak tinggi.

\section{DAFTAR PUSTAKA}

Bahtiar, E.T. 2005. Keandalan Modulus of Elasticity untuk Menduga Kayu Bercacat Akibat Lubang Bor. Jurnal Teknologi Hasil Hutan, 18(2): 80-85.

Hines, W. and C. Douglas. 1989. Probabilita dan Statistik dalam IImu Rekayasa dan Manajemen. UI Press. Jakarta.

Karlinasari, L.. 2003. Pengujian Non Destruktif Kayu Metode Ultrasonic dan Acoustoultrasonik.

Http://tumoutuo.net/702_07134/lina_karlinasar i.pdf. [1September 2006].

de Oliviera, F.G.R., J.A.O de Campos, E. Pletz and A. Sales. 2002. Assessment of mechanical properties of wood using an ultrasonic technique. Proceeding of The $13^{\text {th }}$ International Symposium on Nondestructive Testing of Wood; University of California Berkeley Campus. 19-21 Agustus 2002. Madison: Forest Products Society. pp 75-78.

Surjokusumo, S., N. Naresworo, J. Priyono, dan A.Suroso. 2003. Buku Petunjuk Penggunaan Mesin Pemilah Kayu Versi Panter MPK-5. Laboratorium Keteknikan Kayu, Fakultas Kehutanan, Institut Pertanian Bogor. Bogor.

Walpole, 1995. Pengantar Statistika. Edisi Ketiga. Gramedia Pustaka Utama. Jakarta.

Diterima : 05 Oktober 2009

\section{Syahidah}

Lab. Sifat Dasar dan Teknologi Kimia Hasil Hutan

Fakultas Kehutanan Universitas Hasanuddin

Jl. Perintis Kemerdekaan Km. 10 Tamalanrea, Makassar 90245

E-Mail: idha_unhas@yahoo.com

\section{Tekat Dwi Cahyono}

Program Studi Manajemen Hutan

Fakultas Pertanian Universitas Darussalam Ambon

Jl. Raya Tulehu, Km 24 Ambon - Maluku

Email: tekat@telkom.net 